\title{
DE MUDÉJARES A MORISCOS EN EL REINO DE CASTILLA (1480-1504)*
}

\author{
Ana Echevarría**
}

Los últimos años de permanencia de los mudéjares en el reino de Castilla quedaron profundamente marcados por un periodo especialmente conflictivo, el de la denominada guerra de Granada (1481-1492), la última cruzada contra los musulmanes que tuvo lugar en suelo ibérico. El profundo cambio que sufrieron las condiciones de vida de los musulmanes peninsulares durante los años previos a la guerra, y a lo largo de la misma, no solo afectó a aquellos residentes dentro del emirato granadino, sino también, y muy duramente, a los musulmanes situados en la retaguardia de las tropas. Dentro de esta retaguardia, nuestra atención se va a centrar en los musulmanes que vivían en las ciudades castellanas durante esos últimos años del siglo XV, su relación con los monarcas, y sus contactos con los musulmanes del otro lado de la frontera. Hay que insistir en que las circunstancias que rodearon la forma de vida de los mudéjares durante estos años no son normales -al contrario de lo que se ha pensado durante mucho tiempo-, sino que están profundamente marcadas por las necesidades de la guerra. Ni sus impuestos, ni las limitaciones a las que se vieron sometidos, ni la regulación al milímetro de su vida, costumbres y viajes se habían dado previamente, a pesar del endurecimiento progresivo de sus condiciones de vida desde mediados del siglo XIV. Sin embargo, la guerra cambiaría drásticamente todo eso.

La primera fase que nos interesa es la de preparación de la guerra, pues supuso ya una serie de medidas que afectaron muy directamente a la comunidad mudéjar castellana que podríamos considerar "de retaguardia". La necesidad de convocar una cruzada inmediatamente después de la guerra dinástica que había tenido lugar en Castilla (enfrentamiento contra la hija presuntamente ilegítima del monarca anterior, Enrique IV) y que terminó en 1479 puede entenderse perfectamente en el marco de la legitimación de la pareja real por medio del recurso -tan antiguo en la Península Ibérica- a la lucha contra el infiel, que les per-

* Este artículo se ha realizado dentro del Proyecto de Investigación “Mudéjares y moriscos en Castilla: El caso de Ávila” de la Junta de Castilla y León, con la Dra. Olatz Villanueva como investigadora principal.

** UNED, Madrid. 
mitía igualmente mantener movilizadas a las tropas que ya les habían dado la victoria e, ideológicamente, plantear un frente o una causa común para todos los castellanos, que hiciera olvidar de alguna manera el ascenso irregular de la reina al poder. Como lo principal era conseguir recursos económicos, para cuyo fin comenzaron a solicitar las bulas papales correspondientes -encargadas de proporcionar el "hilo conductor" de la empresa pero también, y sobre todo, de movilizar los recursos de la Iglesia, los más salvaguardados después de cinco años de guerra civil en Castilla-. La primera petición, de 1477, pudo tener como el fin "anticipar" dinero para rematar los gastos de la guerra civil mientras liquidaban la cuestión sucesoria, antes de promover una campaña contra Granada, pero las negociaciones con Sixto IV no fructificarían hasta dos años más tarde ${ }^{1}$. La primera indulgencia plenaria, concedida en 1479 por quince años, se limitaba a la redención de los pecados para quienes acudieran a la campaña.

Paralelamente, se inició también la recaudación entre las minorías religiosas del reino, que en 1480 fueron recluidas en juderías y morerías definitivamente, con fines organizativos y fiscales. Mucho se ha discutido sobre si la reclusión de los mudéjares en morerías fue algo deseado por ellos mismos o impuesto por los monarcas y, en el segundo caso, si esta imposición venía dictada por un deseo de control y salvaguarda de esta comunidad por parte de los reyes, sus máximos valedores. Gracias a las investigaciones recientes estamos en disposición de afirmar que la reclusión general en morerías en Castilla no se impuso hasta la década de 1480, aunque hubo legislación en favor de este desplazamiento de población desde el siglo XIII. Hasta entonces, en casi todas las ciudades castellanas se documenta la existencia de musulmanes viviendo en casi todos los barrios de la ciudad, los intentos infructuosos de los concejos de intentar agruparlos, la existencia de tiendas propiedad de mudéjares fuera de los recintos destinados a ellos, la pervivencia de mezquitas en zonas nominalmente cristianas y las amenazas reiteradas de algunas comunidades de emigrar a tierras de señorío si estas condiciones eran violadas. Aparte, cuando se destinan barrios a los musulmanes, éstos cuentan con una nueva mezquita, baños, carnicerías, tiendas de distintos oficios e incluso cementerios, y también hay amplios testimonios de la presencia de los cristianos dentro de estas morerías para aprovechar estas actividades económicas ${ }^{2}$.

1. J. GoÑ GAZTAMBide, Historia de la bula de cruzada en España, Vitoria, 1958, p. 371. La referencia a estas cuestiones es clara en la bula de 1479, donde el Papa refleja la reciente situación del reino y la necesidad de legitimación de los monarcas: "Ex quo Fernandus rex et Regina prefati, qui quatuor regnis excellentissimis ac aliis regnis et dominiis amplissimis, divina operante clementia, verídica sucessione et iuribus inconcussis dominantur, animadvertentes inter alia Castele et Legionis ac Aragonum regna huiusmodi, que longissimus temporibus variis bellorum strepitibus pro dolor cum grandi sanguinis christiani effussione vexata et conquassata fuerunt, de presenti pace tranquilla et quiete suavissima inter se perfruantur". Idem, p. 654.

2. La investigación mudejarista ha venido tratando este tema en números artículos, pero la documentación más reveladora para la evolución de esta práctica sigue siendo la contenida en el estudio de M.Á. LADERO QuESADA, Los mudéjares de Castilla en tiempo de Isabel I, Valladolid, 1969. 
Los repartidores de las aljamas se pusieron a trabajar, se elaboraron los padrones, se evaluaron las posesiones con motivo del traslado a las nuevas residencias, numerosas mezquitas se amortizaron, y sin duda tuvieron que modificar la composición de los bienes habices que poseían para su mantenimiento -a menudo casas en zonas de las ciudades que iban a ser despobladas por los mudéjares-. Se diseñó un nuevo impuesto extraordinario, el castellano de oro, para gravar a las comunidades minoritarias con el fin de sufragar la guerra, y se anunció su cobro, que se efectuaría en Castilla a lo largo de $1480^{3}$. En ningún momento se plantea la posibilidad de expulsar a estos individuos del reino, o incluso de desplazarlos de sus lugares habituales de residencia, pero sí se revisan los mecanismos de funcionamiento de las aljamas para adecuarlas a las prestaciones que los reyes les van a exigir a partir de ese momento. La obligación de pagar por hacer la guerra a sus correligionarios no era un concepto extraño a los mudéjares, que en un primer momento habían acudido ellos mismos en hueste entre las tropas reales. Sin embargo, acompañada de las otras medidas impuestas debió resultar francamente intranquilizadora a aquéllos que estaban alejados de la frontera y poco acostumbrados a padecer por su causa. El hecho de que la cruzada se anunciase como "definitiva" para expulsar a los musulmanes de suelo peninsular no debía de contribuir a facilitar las cosas.

\section{DURANTE LA GUERRA: EL PROBLEMA DE}

\section{LA CONFLICTIVIDAD INTERNA}

Una vez emprendida la campaña, con los reyes en la zona de la frontera durante la mayor parte del tiempo, era necesario ampliar los mecanismos de control sobre las minorías. Sin embargo, en parte debido a su ausencia del reino, con la consiguiente dificultad para tener asesoramiento en todos los frentes necesarios, y en parte por las dificultades planteadas por las propias aljamas en un tiempo turbulento, debido a la diversidad de su casuística, en este plano los reyes comenzaron ya a fracasar, fracaso que creo está en la base de la posterior política aplicada cuando terminó la conquista de Granada. Desde un principio, los reyes no consiguieron hacerse con el dominio real de la población

3. Los padrones se realizaron en varios años, aunque se han conservado todos; por ej., AGS, RGS, 149103,76 para aljamas de Toledo y Talavera en 1491. Los repartos de castellanos de oro se efectuaron a partir de 1484 entre las aljamas moras y judías, pero en 1491 algunos todavía no se habían pagado, y continuaron haciéndolo durante los años siguientes a la guerra, con quejas continuas y un intento continuo de cambiar los repartos para que fueran menos lesivos para la comunidad. Sobre estos repartos, véase P. ORTEGO, Las comunidades mudéjares del arzobispado de Toledo, ss. XI-XV, Tesina inédita, Madrid, Universidad Complutense, pp. 184-185, 327-328. Agradezco al autor que me permitiera consultar el volumen sin publicar. La documentación referente a las aljamas moras, en AGS, RGS, leg. 148411,81; 149003,410 los de 1484; 148502,260 en 1485; a partir de 1490 en legs. 149103,70; 149103,71; 149102,175; 149505,379; 149702,30; 149209,103; 149210,52; 149103,140. 
mudéjar, y su representante, el alcalde mayor de los moros del reino, no pudo llevar a cabo ese control que se consideraba necesario.

El primer paso fue instituir una autoridad que afectase a todas las aljamas y que fuera suficientemente fiable para los reyes. Este papel lo venía desempeñando el alcalde mayor de las aljamas del reino, provisto de funciones judiciales de última instancia, pero también con capacidades recaudatorias normalmente, al hacerse recaer sobre él siempre la capacidad de repartir los impuestos de las aljamas, a la cabeza de la comisión que realizaba estas tareas. Hasta entonces, el cargo lo habían ocupado personajes de la confianza de los monarcas o de su consejo real, pero en este momento se hacía imprescindible una persona de la máxima seguridad. Se recurrió a Abrahen Xarafí, al que la reina había nombrado ya alcalde mayor de las aljamas de sus dominios cuando era princesa, oponiéndose al alcalde de Enrique IV. A partir del comienzo de la guerra, las confirmaciones en el cargo de este personaje se sucedieron, ante la oposición absoluta de las aljamas castellanas a aceptarle y recibirle como autoridad máxima de su comunidad. El conflicto se mantuvo durante toda la guerra, por lo que puede decirse que esta parte del plan director de las relaciones con los mudéjares fracasó. Por ello, tampoco puede decirse que se triunfara en una de las principales preocupaciones de los reyes, que era sin duda mantener la paz interna de las aljamas de la retaguardia durante la guerra, para evitar que los conflictos internos pudieran redundar en revueltas de esa quinta columna que existía en el interior del reino, o en defecciones que aumentaran el número de las tropas granadinas. Dentro de esa cuestión de la paz interna se encontraba también el relativamente elevado número de demandas y juicios criminales entablados contra mudéjares en esa época, cuyas multas y confiscaciones de bienes de los asesinos pasarían a engrosar el patrimonio regio. Esta conflictividad no tiene por qué ser mayor que en otros momentos, simplemente nos es más conocida en este periodo por el recurso a abogados y jueces cristianos para juzgarlas, y la centralización de las causas en la audiencia y chancillería reales, lo que ha permitido que se nos conserven los documentos correspondientes ${ }^{4}$. Aunque ésta puede ser la pauta general en la Castilla bajomedieval, estimamos sin embargo que sí hay una cierta intensificación en las luchas internas dentro del grupo mudéjar a lo largo de las últimas décadas del siglo $\mathrm{XV}$, debido también a la falta de liderazgo claro en las comunidades, como intentaremos demostrar más adelante.

Dejando de lado las causas que se refieren a cuestiones civiles diversas, como la devolución de tierras dadas en tenencia, los repartos de herencias o los acuerdos de dote, que existen pero entendemos no presentan una casuística fuera de lo normal respecto a otras comunidades mudéjares, sí creemos que es

4. M. Meyerson, The Muslims of Valencia in the Age of Fernando and Isabel. Between Coexistence and Crusade, Berkeley, 1991, pp. 209, 216, 218-220, no ve una gran diferencia entre la criminalidad del grupo mudéjar y la de la sociedad cristiana. 
interesante observar el creciente número de casos de apelación juzgados por la Real Chancillería castellana, primero en Salamanca y luego en Valladolid, con asesoramiento de jurisconsultos musulmanes, lo mismo que ocurría entre los judíos ${ }^{5}$. Durante el transcurso de la guerra, se registraron varios casos de homicidio, pero también de agresiones dentro de distintas aljamas, que llevan a pensar en un endurecimiento de las condiciones de los mudéjares y un enquistamiento de los problemas naturales en todo grupo de vecinos que desembocaban en una violencia de la que no tenemos noticia para otros periodos ${ }^{6}$.

Aunque se ha señalado que el homicidio no es un crimen de elevada frecuencia entre los mudéjares, lo que contribuyó incluso a que fueran excluidos de la pena de muerte resultante en algunas localidades ${ }^{7}$, hubo evidentemente excepciones $^{8}$. Puede deducirse de este bajo índice de criminalidad mortal el estrecho control al que estaba sujeta la población mudéjar, así como por otra parte la discreción que les caracteriza -esa forma de mantener un "perfil bajo" que no les señalara entre el resto de la población-. Curiosamente, la violencia estaba dirigida normalmente hacia una persona externa a la comunidad. Es evidente que en estos últimos años del siglo XV, sin ser mayoritario, el homicidio sí hace su aparición de una forma que antes era desconocida. En la década correspondiente a la guerra, contamos con varios procesos interesantes, que

5. Ver los recientes estudios de M.A.VARONA GARCía, «Judíos y moros ante la justicia de los Reyes Católicos. Cartas ejecutorias de la Real Chancillería de Valladolid (1476-1495)», en Proyección histórica de España en sus tres culturas, Valladolid, 1993, I, pp. 337-367, especialmente pp. 344-348, y Cartas ejecutorias del Archivo de la Real Chancillería de Valladolid (1395-1490), Valladolid, 2001, docs. n. 231, 368, 452, 665, 744, 825, 832, 1216, 1245, 1318. Sobre qué tipo de casos se juzgaban por jueces de arbitrio musulmanes, alcaldes mayores o autoridades cristianas, el estudio sistemático para Castilla está aún por hacer, pero parece coincidir en muchas de sus líneas con lo establecido por M. MEYERSON, op. cit., pp. 194-201. Sin embargo, la oposición entre el batlle general y los de las distintas circunscripciones en cuanto a quién juzgaba a los mudéjares parece tener menos importancia en Castilla, al no producirse una confrontación tan importante entre los corregidores reales y los alcaldes.

6. Fuera de la Chancillería y en fechas posteriores, contamos con dos casos más: un pleito por homicidio, juzgado por un alcaide cristiano en representación de la sede de Cartagena y dos alcaldes moros según la sunna. La pena aplicada fue de ahorcamiento ejemplarizante desde las almenas del castillo de Alcantarilla, sentencia publicada por J. TORRES FONTES, «El alcalde mayor de las aljamas de moros del reino de Castilla», Anuario de Historia del Derecho Español, 1962, pp. 131-182, esp. pp. 170-171. El otro, con sentencia de marzo de 1501, enfrentó a Abdalla, moro vecino de Ávila, con Juan Barrado, vecino de Ávila, sobre agresión y homicidio, Real Chancillería, RCE, c. 156-38.

7. F. SEGURA URRA, «Los mudéjares navarros y la justicia regia: cuestiones penales y peculiaridades delictivas en el siglo XIV», Anaquel de estudios árabes, 14, 2003, pp. 239-257, esp. pp. 252-253.

8. Ibidem, p. 252, señala un asesinato cometido en la Merindad de la Ribera contra un judío (1319), igual que consta otro en Segovia de un judío, Lesar Albohacén, pero finalmente se exculpa al alfaquí Abseyt acusado de haberlo cometido, AGS, RGS, agosto 1476, f. 569. Dos casos más, el del presunto asesino madrileño Abrahem de Robredo (1444) y el del crimen pasional de Hamete Romayne, que asesinó al amante de su mujer, Mahomad de Madrid (1484), en P. ORTEGO, op. cit., p. 124. 
fueron resueltos en apelación por la sala de lo criminal de la chancillería, y no por el alcalde mayor de las aljamas, como hubiera sido deseable de no haber mediado protestas de los propios musulmanes. Los casos son los siguientes:

a) En los momentos anteriores a la campaña, Fátima, esposa de Abraham de Torres, vecino de Madrid, denunciaba a Abraham de Gormaz como asesino de su esposo a la puerta de su casa, en la morería vieja de San Andrés. La sentencia recoge perfectamente el ambiente prebélico del momento, pues los alcaldes del crimen condenan a Abraham de Gormaz a pagar y enviar a su costa a un peón espingardero cristiano "a la guerra de los moros", en servicio del rey, mientras quedaba confinado en las casas del alcalde de casa y corte mientras duraba la campaña. No sabemos si después de ésta sería represaliado de alguna otra manera9

b) La causa de Abraime Perogil contra Amet el Corto y Abdallá de las Navas por la muerte de su hermano, Aly Perojil, en Ávila (1490), que había sido juzgada en primer lugar por el alcalde Andrés Moreno de Ávila, que había dictaminado la muerte de Abdallá de las Navas y el destierro perpetuo de Amet el Corto ${ }^{10}$. Éste apeló a la sentencia ante el otro alcalde de la ciudad, el bachiller Cristóbal de Benavente, quien redujo su pena de destierro a un año, a lo que apeló de nuevo Abraime Perogil ante los reyes, consiguiendo que se revisase el caso y se condenara a Amet el Corto, en su ausencia y rebeldía, a que le fuera cortada la mano derecha y puesta en la picota. Se aplica, pues, una pena extremadamente rara en el derecho cristiano de esta época, que probablemente tuviera precedentes en el islámico.

c) Otro caso, quizá uno de los más sonados y desde luego el mejor documentado de Ávila, es el pleito celebrado en Olmedo durante los años 1492-1493 entre Yusuf el Rico y Alí Moharrache por el asesinato del hijo del primero, Abdalla el Rico, en el que se implicaron de una manera u otra los principales nombres de la aljama abulense ${ }^{11}$. Alí Mo-

9. 1486, diciembre, 4. Salamanca. Real Chancillería, RCE, c. 6-5. Cit. M.A. VArona GARCíA, «Judíos y moros...», p. 350; Cartas ejecutorias, pp. 108-109, doc. 231. Estudiado brevemente en P. ORTEGO, op. cit., pp. 125-126.

10. Real Chancillería, RCE, c. 29-32. Cit. en M.A. VARONA GARCíA, «Judíos y moros...», p. 359 y Cartas ejecutorias, p. 516, doc. 1318.

11. J. JIMÉNEZ GADEA, «Acerca de cuatro inscripciones árabes abulenses», Cuadernos abulenses, 31, 2002, pp. 25-71, y del mismo autor, «Estelas funerarias islámicas de Ávila: clasificación e inscripciones», Espacio, Tiempo y Forma. Serie I, Nueva época. Prehistoria y Arqueología, 2009, pp. 205-252. Agradezco mucho al autor que me permitiera consultar esta obra antes de su publicación. El pleito puede seguirse a través de los siguientes documentos: J.L. MARTín RoDRíGUEZ, Documentación medieval abulense en el Registro General del Sello Vol. VII (4-I-1492 a 24-XII1492), Ávila, 1996, pp. 146-148, 150-151, docs. 57, 59; C. LuIS LÓPEZ, Documentación medieval abulense en el Registro General del Sello Vol. VIII (5-I-1493 a 28-VII-1493), Ávila, 1995, pp. 4046, 51-53, 88-92, docs. 4-6, 9, 23-24, y Documentación medieval abulense en el Registro General del Sello Vol. IX (30-VII-1493 a 14-IV-1494), Ávila, 1996, pp. 27-29, 71-74, 97-98, docs. 8, 27, 36. 
harrache había dado una puñalada en la cabeza a Abdalla, que fue enterrado en el cementerio de rito islámico (almacabra) de Ávila en un magnífico sepulcro de tres cuerpos, con una inscripción coránica en árabe que ha permitido identificar al yacente con el fallecido protagonista del juicio ${ }^{12}$. Lo mismo que en el caso anterior, el culpable había huido y la justicia ordenó prenderlo y conducirlo a juicio, al tiempo que se citaba a todos los testigos que pudieran dar fe de lo ocurrido, entre ellos el conocido Yuçafe Palomero, miembro de otra destacada familia abulense. Éste también se encontraba preso por su implicación en otra demanda - de hecho, los Palomero eran visitantes asiduos de la Chancillería y del notario-. Una vez ejecutado Alí Moharrache, Yusuf el Rico tuvo que pedir protección para él y su familia a las autoridades frente a posibles represalias por parte de la familia del asesino, a cuya viuda Haxa se le imputan los costes del pleito (nada menos que 34.072 maravedís). Ésta alega, por medio de un tutor, como lo exige el derecho islámico por su condición de mujer, que está arruinada y no puede hacer frente al pago, por lo que se ordena una tasación de sus bienes ${ }^{13}$.

La queja de un musulmán por la agresión recibida de otro de los mudéjares de Ávila mientras estaba rezando en el cementerio abre el capítulo de los pleitos sobre malos tratos y agresiones. Los protagonistas de la denuncia pertenecen a las familias de dos de los prestamistas que aparecen en el documento mencionado, Abdalla Redondo y Mahomad Palomero. El primero habría apaleado al segundo mientras oraba en el cementerio hasta romperle la cabeza. Los Reyes Católicos ordenan prenderle y conducirle a juicio ${ }^{14}$. Éstos se suceden una vez terminada la guerra (1494-1497) en diversas ciudades castellanas ${ }^{15}$ : Valladolid, Ágreda, Ávila, etc. Frente a la persistente pena de caloña con la que se castigaban estos crímenes en Navarra ${ }^{16}$, y aunque las multas también eran el castigo predominante en Castilla, aquí nos encontramos también con otras sentencias mucho más duras, como cortar la mano a Hamed de Madrid, vecino de Valladolid, culpable de malos tratos contra Farax de la Rúa. Es posible que las penas se redimieran con multas, pero la evidencia no es tan firme como en Aragón y Navarra, donde la multa se aplicaba directamente sin mencionarse siquiera la pena canónica original.

Uno de los pleitos civiles más interesantes del periodo es el que enfrentó a las descendientes de maestre Alí Caro Alfageme, miembro de una de las fa-

12. Debemos este excepcional descubrimiento a J. JIMÉNEZ GADEA, «Acerca de cuatro inscripciones...», p. 47.

13. Ibidem, p. 43.

14. L. LÓPEZ, Documentación medieval, Vol. IX, pp. 36-38, doc. 12. Véase la nota 23.

15. M.A. VARONA GarCía, «Judíos y moros...», pp. 366-367, registros 107, 109, 113. Los documentos, en Real Chancillería, RCE, c. 76-41, 114-16 y 152-13.

16. F. Segura UrRa, op. cit., pp. 248-249. 
milias más importantes de Ávila, que se extinguiría debido a la falta de herederos masculinos, y cuyos yernos se repartieron la fortuna e influencias del rico boticario ${ }^{17}$. Varios de estos mudéjares vieron su condición económica y social tan elevada que son los que ostentan el liderazgo -compartido- de la comunidad, instalándose en los nuevos terrenos que se les facilitan en la nueva morería "cabe la Trinidad", en casas pertenecientes al monasterio premostratense de Sancti Spiritus, que sustituye así a la catedral de Ávila como principal institución que entrega sus casas a censo a musulmanes. De hecho, en los nuevos contratos se ve una clara continuidad entre la legislación que regía los contratos de los musulmanes con la catedral y la que regulará sus censos con el monasterio ${ }^{18}$. Entre ellos figura alguno de los ricos mudéjares -Çale Redondoque prestarán dinero incluso a los Reyes Católicos para continuar la guerra en Granada, como veremos a continuación ${ }^{19}$.

\section{MEDIDAS DE GUERRA: FINANCIACIÓN Y COMERCIO}

Volviendo al marco religioso cruzado requerido para la ejecución de la campaña, es evidente que la bula de 1479 era insuficiente para los propósitos de los Reyes Católicos, tanto material como espiritualmente. Las necesidades bélicas requerían una financiación extraordinaria, a cuya consecución se dedicó el rey, y que se plasmó en un nuevo documento en 1482 que preveía la lucha en los dos frentes cruzados del momento -el turco y la Península Ibérica-, y la posibilidad de recaudar en Castilla, Aragón y Sicilia una décima sobre los frutos y rentas decimales de un año a todo el clero, incluido el secular y las órdenes. En 1485 se produjo un enfrentamiento con el nuevo pontífice, Inocencio VIII, a costa de la tercia que se había reservado para la guerra contra los turcos. La campaña granadina ya estaba avanzada, y las cantidades se habían empleado junto con las correspondientes a los reyes, por lo que las dificultades para devolverlas a Roma eran ímprobas. Finalmente, y gracias también a los triunfos obtenidos en el campo de batalla -toma de Ronda, utilizada convenientemente en la diplomacia-, Inocencio VIII dio su brazo a torcer y renunció a la tercia, prorrogando la bula sucesivamente en 1485 y 1487. El documento expedido en octubre de 1489 prorrogaba la cruzada por un año más y concedía una nueva décima del clero, pero ordenando que se revisasen los abusos de los recaudadores reales; la última renovación se realizó mediante la bula de 1 de octubre de $1491^{20}$.

17. Sobre la familia véase A. ECHEVARRíA, «Los Caro de Ávila, una familia de alfaquíes y comerciantes mudéjares», en Biografías mudéjares. La experiencia de ser minoría: biografías islámicas en la España cristiana, ed. A. Echevarría, Madrid, 2008, pp. 203-232.

18. AHN, Clero Secular-Regular, Ávila, leg. 534.

19. Real Chancillería, Pleitos civiles, c. 1351-5.

20. J. GoÑ GAZTAmbide, op. cit., pp. 385-393. 
Precisamente la necesidad perentoria de fondos alternativos hizo que, aprovechando la "correcta" relación entre los reyes y sus súbditos musulmanes, se recurriera a solicitar préstamos a los miembros más acaudalados de las aljamas musulmanas $-y$, suponemos, judías- para sufragar gastos de guerra. Uno de los casos que mejor documentado está es la petición a los ricos mudéjares de Ávila, a principios de 1483, cuando estaban siendo derrotados por Muley Hacén en la Ajarquía de Málaga ${ }^{21}$. Probablemente los empréstitos fueron "obligatorios". Todos los musulmanes contribuían con cantidades de 10.000 maravedíes, salvo don Abrahén Herrador y maestre Abrahén Fresneda, que lo hacían con 15.000, que fueron recogidos por Francisco de Luzón, corregidor de Madrid. Los préstamos fueron devueltos en enero de 1488 -es decir, 5 años después-, a través de Mofarrache del Camino, que quedó encargado de cobrarlos de Fernando Bravo, tesorero de las bulas de cruzada que estaba en Salamanca. Parece que, en un momento de estrechez, y a cuenta de fondos que esperaban conseguir, los reyes acudieron a formas extraordinarias de conseguir los fondos para la guerra, que devolvieron tan pronto los fondos papales estuvieron disponibles. Los nombres de los interesados coinciden en ambos documentos, el de cobro y el de la constitución del poder notarial para que uno de ellos cobrase la deuda ${ }^{22}$. No deja de ser paradójico que estos musulmanes puedan dirigirse en persona a recuperar las cantidades prestadas, precisamente del tesorero encargado a su vez de cobrar las bulas de cruzada.

El intento de centralizar la organización de las aljamas y el recurso a alcaldes mayores y alfaquíes como asesores legales de la corona en materia de derecho islámico ${ }^{23}$-el que se había permitido mantener a las comunidades mudéjares mediante las capitulaciones firmadas con ellos- facilitó la intervención real en otras facetas que permitirían también manipular al grupo y obtener mayores ingresos, sobre todo cuando la guerra avanzó y las bulas papales eran insuficientes para proveer de suficientes fondos a las tropas castellanas. La asesoría de especialistas musulmanes aparece mencionada explícitamente en los

21. F. Vidal CAStro, «Historia política», en El reino nazari de Granada, Historia de España Menéndez Pidal (coord. M.J. Viguera Molins), Madrid, 2000, vol. VIII.3, pp. 77-251, esp. p. 196.

22. 1483, febrero, 14, Madrid. D. CABAÑAs GonZÁLEZ, Documentación medieval abulense, I, pp. 24-25, doc. 6. El poder para la restitución, 1488, enero, 13, Ávila. AHPAv, Prot. 420, f. 294 r: "Poder. En Avila este dia yo don Aseyte el Gallo e Abdalla de Santo Tomé e Çale Redondo e Brayme Frexneda e Caçime Açamor e Aly Mofarache por mi en nombre de Brahyme Ferrero mi tyo, por el qual me oblygo de estar e faser estar, moros vesinos de Avila, consçemos que damos poder bastante segund lo nos avemos a vos Mofarrache del Camino moro vesino de Avila para que en nuestro nombre e de cada uno de nos recabdes e cobres de Ferrand Bravo vesino de Salamanca, tesorero de las buldas, todas las quantyas de maravedis contenidas en çiertos lybramientos que en el nos fue lybrado por Ferrando de Peralta reçebtor de los enprestitos desta çibdat del año postrymero que paso de nuestros enprestydos que fesymos al rey e la reyna nuestros señores, e para dar carta de pago e para enjuysyar otorgamos carta fyrme etc. Testigos Abdalla Ferrero e Aly Caro de la Calle e Alafe fijo de Farax vesinos de Avila".

23. Sobre cómo se realiza esta adaptación, véase A. ECHEVARRÍA, «De cadí a alcalde mayor. La elite judicial mudéjar en el siglo XV», Al-Qanțara, XXIV-1, 2003, pp. 139-168 y XXIV-2, 2003, pp. 273289 y «Pautas de adaptación de los mudéjares a la sociedad castellana bajomedieval», Actas del IX Simposio Internacional de Mudejarismo, Teruel, 2004, pp. 47-60. 
documentos reales a la hora de modificar su relación con sus súbditos musulmanes: "segund paresçe por pesquisa e ynformacion avida en el mi consejo de alfaquiques e moros" ${ }^{24}$. Uno de los casos más llamativos es el intento de apropiarse de los bienes vacantes dejados por los musulmanes fallecidos sin herederos, expediente al que recurrió la reina durante el año 1489 para intentar recabar fondos urgentemente para la campaña.

Las herencias intestadas aparecían recogidas en los manuales de figh, donde se especificaba cuidadosamente el grado de las relaciones familiares con derecho a reclamar dichos bienes, que si no quedaban para el tesoro. En el reino de Aragón, como queda atestiguado en Huesca, el monarca confiscaba todos los bienes de los musulmanes fallecidos intestados ${ }^{25}$. No es por tanto raro que amparándose en esta práctica, los reyes requirieran al corregidor de Ávila y al de Segovia para que informasen de cuántos musulmanes habían fallecido en estas ciudades sin herederos, para que la totalidad o dos tercios de sus bienes pasasen a la cámara real ${ }^{26} \mathrm{y}$, cuando estas gestiones no llegaron a buen puerto, la reina enviara a uno de sus propios criados a realizar las indagaciones pertinentes. Con esta decisión, también se evitaba el que otros mudéjares se hicieran con la posesión momentánea de los bienes para enviarlos más tarde a los familiares que el difunto pudiera tener en Granada, como ocurrió en 1483 con Farax Baydaçi de Toledo ${ }^{27}$.

Por otra parte, no todas las medidas tomadas durante la guerra fueron en detrimento de las aljamas mudéjares del norte del reino: algunas de ellas iban encaminadas a proteger su estatus, poniendo en cuestión la idea de que la homogeneización confesional que se emprendió una vez terminada la ofensiva contra Granada fuera fruto de un diseño previo totalmente elaborado a lo largo de los años anteriores. Parece que en la voluntad de los reyes coexisten todavía al mismo tiempo la tradición del cuidado de sus súbditos musulmanes, considerados a todos los efectos como vecinos del reino -a pesar de la numerosa legislación en contra, los protocolos notariales de estos años se empeñan en citar a estos musulmanes como vecinos de pleno derecho de las ciudades, aunque el uso del trato de respeto "don" para los principales de la aljama va desapareciendo paulatinamente ${ }^{28}$ - y protegidos de la corona, y por otra parte, la

24. B. Casado Quintanilla, Documentación real del archivo del concejo abulense, 1475-1499, 1994, p. 136.

25. B. BASÁÑEZ, La aljama sarracena de Huesca en el siglo XIV , 1989, p. 105. S. ABBOUd HAGGAR, «Precedentes andalusíes en la fiscalidad de las comunidades mudéjares», En la España Medieval, 31, 2008, pp. 475-512, esp. p. 509.

26. Los documentos especifican que se tiene conocimiento de que son muchos. Para Ávila, B. CASADO, op. cit., pp. 112-113, 135-137. Para Segovia, P. ORTEgo, op. cit.

27. J.E. LÓPEZ DE COCA, «La emigración mudéjar al reino de Granada en tiempo de los Reyes Católicos», En la España Medieval, 26, 2003, pp. 203-226, esp. p. 207.

28. Son muestra los numerosos documentos notariales encontrados en el Archivo Histórico Provincial de Ávila, en los que se menciona siempre a los líderes de la comunidad, alfaquíes e imanes de la mezquita, con el título don. Igualmente, es generalizado el tratamiento de doña para las mujeres prominentes, fuera por su vinculación familiar, o por ejercer un oficio prestigioso, como el de comadronas. 
imposición de la fe cristiana por medio de la conversión de este colectivo, tal como exigían los ideales de cruzada imperantes.

Ya hacía tiempo que las aljamas reclamaban a los reyes la protección contra las autoridades locales -corregidor y alcaldes-, que pretendían reclamarles ropas y el pago de las velas de las ciudades, impuestos que no estaban obligados a pagar, sobre todo cuando no se hacían velas nocturnas ${ }^{29}$.

El resto de las medidas favorables de la corona tuvieron que ver con la protección del comercio, tan necesaria en tiempos de guerra para evitar que se colapsara la parte central del reino. Una gran parte de los mudéjares de Ávila se dedicaban a la producción textil, que en general ocupaba a casi un $50 \%$ de la población, lo mismo que en Segovia. Es más, el de los paños es uno de los negocios en los que los mudéjares consiguen destacar como mercaderes-fabricantes, empleando incluso a operarios cristianos a pesar de las normativas en contra. Muy relacionada con esta ocupación era la del transporte, fuera en la faceta de arriero, de tratante de ganado, o de mercader a larga distancia conectado con el transporte de materias primas para el trabajo textil de la zona ${ }^{30}$. Esta actividad puede considerarse imprescindible, dada la naturaleza montañosa de la zona: parte de su monopolio pudo venir propiciado por su ejercicio continuado durante las guerras que diezmaron -o al menos mantuvieron ocupada- a la población masculina castellana entre 1480 y 1492. Es en ese contexto en el que debemos entender las cartas de obligación de venta de ganado destinado a la arriería ${ }^{31}$. También se quejaban de la duplicación de los impuestos (la sisa, concretamente) sobre paños, lanas y otras mercancías, que debían pagar por un lado a la Hermandad, y por otra al concejo, con lo que su participación en las ferias y el comercio urbano quedaba seriamente gravada. Dado que durante la guerra buena parte del abastecimiento de la ciudad quedó en sus manos -a excepción de la carnicería, vedada por los reyes seguramente a causa de las medidas, estas sí, religiosas al respecto- se comprende que tanto los mudéjares como los propios vecinos que quedaban en Ávila protestasen de su situación ${ }^{32}$. Éstos se quejaban amargamente de la falta de abastecimientos debido a que no se permitía a los moros y judíos vender alimentos a la ciudad ${ }^{33}$. En

29. P. León Tello, Los judíos de Ávila, Ávila, 1963, pp. 55-58, doc. XI. También AGS, RGS, X-1480-109.

30. Son notables los protocolos en los que los mudéjares dejan como prenda de préstamos cantidades importantes de telas ricas: AHPAv., S. de TAPIA, La comunidad morisca de Ávila, Salamanca, 1991, pp. 71, 112.

31. AHPAv, Prot. 420, ff. 21-88 y 259-307, se incluyen por error varias hojas de 1487-1488.

32. P. LeÓN Tello, op. cit., pp. 69-70, doc. XVIII; 79, doc. 24.

33. "Todos los recueros son moros y el trabto e conversacion de la dicha cibdad esta en moros e judios, e agora nuevamente vos las dichas justicias aveys vedado e defendido que los dichos moros e judios non vendan pescado ni sardyna ni myiel ni aseyte ni otras cosas de comer, en lo qual la dicha cidbad e vesinos e moradores della reçiben grand agravio". AGS, Sello, 28-V-1488, f. 8. P. LEÓN TELLO, op. cit., p. 79, doc. 24 y T. Sobrino ChOmón, Documentos del Archivo Municipal, II, p. 249, doc. 207. S. de TAPIA, op. cit., pp. 74, 77. 
otras ciudades, como Valladolid, la importancia de los mudéjares en el abastecimiento de la ciudad aconsejó liberarlos de las limitaciones impuestas por los guetos, y permitirles tener tiendas en los barrios ya cristianos, a pesar de que siguieran residiendo en las morerías ${ }^{34}$.

Esta implicación en el tránsito de bienes demuestra que, en contra de lo que se ha dicho anteriormente, la capacidad de viajar de los mudéjares, aunque limitada, no era inexistente. Y no solamente dentro del propio reino, o entre Castilla y Portugal ${ }^{35}$, sino incluso al reino de Granada. Si el viaje se planteaba como una gestión de algún tipo, se procuraban los correspondientes salvoconductos de los reyes, pero si se contemplaba una emigración definitiva, evidentemente debía hacerse subrepticiamente. Están ampliamente documentados ambos $\operatorname{casos}^{36}$.

La vida de las comunidades musulmanas castellanas fuera del marco estricto de la frontera granadina, inestable precisamente por encontrarse precisamente en guerra, manifiesta por lo tanto una doble faceta de continuidad, por una parte, y empeoramiento en cuanto a las limitaciones que se les imponen. Sin embargo, terminada la guerra, las circunstancias no mejoran, y la incapacidad de los reyes para terminar de diseñar un esquema político para la minoría musulmana -puesto que la judía ya ha quedado definitivamente excluida- que fuera válido tanto para los "antiguos mudéjares" como para los granadinos recién lle-

34. 1489, marzo, 24. Medina del Campo. "Sepades que por parte de los moros çapateros e borçeguineros e otros ofiçiales moradores de la dicha villa de Valladolid, nos fue fecha relaçion por su petiçion que ante nos en el nuestro consejo fue presentada diziendo que segund lo que por nos fue determinado e mandado al tienpo que se fiso el apartamiento de los moros de la dicha villa, ellos pueden tener sus tyendas e ofiçios fuera de la moreria de la dicha villa e estar labrando en ellas e vendiendo sus mercaderias, e diz que vos las dichas justiçias e alguasyles de la dicha villa aveys intentado de los non dar lugar en que tengan fuera de la dicha moreria sus tyendas e ofiçios e mercaderias, e los aveys querido prendar sobrello, en lo qual diz que sy asy oviese de pasar, que ellos reçebirian grand agravio e daño, e nos suplicaron por merçed cerca dello con justiçia les mandasemos proveer o como la nuestra merçed fuese, e nos tovimoslo por bien. Porque vos mandamos a todos e a cada uno de vos que, de aqui adelante, dexeis e consintais a los dichos moros de la dicha villa tener fuera de la dicha moreria, en la plaça e calles publicas de la dicha villa sus tiendas e ofiçios e labrar en ellas e vender sus mercaderias, e sobrello no les prendays ni prendeys ni consyntays prendar ni prender, ca nos por esta nuestra carta les damos liçençia e facultad para que puedan estar e tener las dichas sus tiendas e ofiçios fuera de la dicha moreria en la plaça e calles publicas de la dicha villa donde ellos quisieren, con tanto que sean tiendas pequeñas e no casas de morada e que no puedan comer ni dormir en ellas de noche". Archivo General de Simancas, R.G.S., Mayo 1500,f. 35 (inserta). Ed. M.Á. LADERO QUESADA, op. cit.

35. F. BARros, Tempos e espaços de mouros. A minoria muçulmana no reino português (séculos XII a $X V)$, Lisboa, 2007.

36. Para el primero, ver el ejemplo de las familias de Omar, alfaquí de Segovia y Mahomad Calderero, autorizados a trasladar también a cuantas familias mudéjares quisieran salir de Granada en febrero de 1480, cuando los preparativos de la guerra ya estaban avanzados, en A. ECHEVARRÍA, «Las aljamas mudéjares castellanas en el siglo XV: redes de poder y conflictos internos», Espacio, tiempo y forma. Sección III-Historia Medieval, 14, 2001, pp. 93-121. Para emigrantes, varios casos en J.E. LÓPEZ DE COCA, «La emigración mudéjar del reino de Granada en tiempo de los Reyes Católicos», En la España medieval, 26, 2003, pp. 205-207. Entre los alarifes y artesanos llegados para arreglar la Alhambra para los Reyes aparecen también varios mudéjares castellanos, idem, p. 209. 
gados a este estatuto es fundamental a la hora de entender el fracaso final de los marcos de socialización, que conduce a la conversión generalizada. Es evidente que la caída de Granada y los hechos posteriores, la expulsión de los judíos y el pensamiento político de los Reyes Católicos y sus contemporáneos fueron los tres factores principales que decidieron el fin de la minoría islámica en el reino de Castilla. Pero las medidas de guerra fueron allanando el terreno durante las dos décadas anteriores: la "anormalidad" de las limitaciones para el grupo mudéjar se fue convirtiendo en "lo habitual", y borrada la memoria de tiempos mejores, las aljamas no pudieron reaccionar para regresar al statu quo anterior a la guerra. El empeoramiento de su situación económica y la falta de liderazgo hicieron el resto, y causaron un aumento de la conflictividad interna que puede medirse en su recurso a la justicia cristiana. Sin embargo, no podemos extrapolar esta situación a periodos anteriores: lo que nos enseña la investigación sobre el mudejarismo en los últimos años es que el proceso que siguieron las aljamas mudéjares fue largo y complejo, y queda mucho por conocer de la forma en que se reguló su situación en los siglos XIII y XIV. A este periodo, también estudiado por el Prof. Epalza, dedicaremos redoblados esfuerzos, para tratar de arrojar luz sobre una minoría que cada vez conocemos mejor.

\section{RESUMEN}

En los últimos años del siglo $\mathrm{XV}$, coincidentes con la fase final de la guerra de Granada, las condiciones de vida de los mudéjares castellanos van a empeorar notablemente. Las circunstancias de la guerra van a influir mucho tanto en los ámbitos legal, económico y político de la vida de los mudéjares como en el pensamiento político de los Reyes Católicos hacia las minorías de sus reinos. El fallido intento de aquéllos por controlar a las comunidades mudéjares conducirá a la decisión de la conversión general a comienzos del siglo XVI.

Palabras clave: mudéjares, moriscos, guerra de Granada, Reyes Católicos, legislación.

\section{ABSTRACT}

In the last years of the $15^{\text {th }}$ Century, in coincidence with the final stage of the Granada War, life conditions of the Castillian Mudejars are going to experience an important degradation. The consequences of war will have great influence in several spheres of life, particularly the legal, economic and politic ones, both from the Mudejar perspective and from the Catholic Kings policy towards the minorities in their kingdoms. Their failed attempt to control the $\mathrm{Mu}$ dejar communities will force the decision of the general conversion at the beginning of the $16^{\text {th }}$ Century.

Key words: Mudejars, Moriscos, Granada War, Catholic Kings, legislation. 